\title{
A 9-hour biochemistry exam. An iron man competition or a good way of evaluating undergraduate students?
}

\author{
Alexandre B. Sé; Euler Nascimento; Marcelo Hermes-Lima \\ Depto Biologia Celular, UnB, Brasília, DF, 70910-900
}

In a previous work we discussed the capability of peer-tutors to write good true-or-false biochemistry exams (Sé et al. Are tutor-students capable of writing good biochemistry exams? SBBq 2004, abstract K-18). We are currently reporting the experience of 12 semesters in which a pair of peer-tutors, coordinated by a professor, write a discursive exam. It has themes like obesity, cholesterol, diabetes and alimentation as described in Passos et al, A lunch of pizza and pasta used for the learning of metabolic biochemistry, SBBq 2003, abstract K-10. The themes are chosen based on 2 articles from important international journals, such as the American Journal of Physiology. These articles have been previously discussed in an Advanced Biochemistry class with all peer-tutors and the professor. The questions are based in practical situations, according to what was exposed previously in a text, which is written by the peer-tutors and based on the articles. The focus of the exam is the discussion of the situation exposed and the development of a line of thoughts instead of just memorizing biochemical concepts. In order to facilitate this process, the students are divided in pairs to answer the questions (they must have a difference in the previous exam grade lower than 1.3). They are allowed to bring books and class notes to the test to help the discussion. To avoid the rush and let the students discuss and think freely, they have 9 hours to do the exam. During this period, we evaluated the quality of the 9-h-exam by a survey at the end of it. When asked to give a 0 -to-4 score regarding (a) the difficulty level of the exam (4 mean very hard), (b) if the exams makes an appropriate evaluation of biochemical knowledge (4 mean it does) (c) if the exams make you reason about applied biochemistry (4 mean it does), the scores were $3.14,3.61$ and 3.82 respectively $(n=469)$. Our survey show the students good acceptance of the 9-h-exam. The grades along 12 semesters have a mean of $6.65+-$ 1.70 with a Gaussian-type distribution $(\mathrm{n}=739)$. We can conclude that the exam has good quality and acceptance, and seem to be an alternative way of evaluating undergraduate medical and nutrition students. Support: CNPq 